\title{
A Risk Evaluation Method for Fatigue Damage of Airport Concrete Runway
}

\author{
Shuai Fu ${ }^{1,2}$, Kai Sheng ${ }^{3}$, Qingmin Qi ${ }^{1,2}$, Feiyin Wang ${ }^{4,5, *}$ and Ao Sun ${ }^{6}$ \\ ${ }^{1}$ School of Civil Aviation, Zhengzhou University of Aeronautics, Zhengzhou 450000, China \\ ${ }^{2}$ Henan Joint International Research Laboratory of Civil Aviation Safety and Reliability, Zhengzhou University of Aeronautics, \\ Zhengzhou 450000, China \\ ${ }^{3}$ Shenzhen Urban Public Safety and Technology Institute, Shenzhen, Guangdong 518000, China \\ ${ }^{4}$ National Key Laboratory of Air Traffic Operational Safety Technology, Civil Aviation University of China, Tianjin 300000, China \\ ${ }^{5}$ Research Institute of Civil Aviation Safety, Civil Aviation University of China, Tianjin 300000, China \\ ${ }^{6}$ School of Aerospace, Transport and Manufacturing, Cranfield University, Bedfordshire, MK430AL, UK
}

Received 2 March 2021; Accepted 15 August 2021

\begin{abstract}
Fatigue damage of airport runway is an important factor affecting airport safety management. To recognize the fatigue failure risk factors of airport concrete runways, an integral analysis of the internal and external causes of the fatigue failure of runways was conducted, which extracted 18 risk factors. The evaluation results of risk factors were calculated by the threshold, expert scoring, and G1 method, the comprehensive evaluation results of concrete runway risk were obtained by layer-by-layer coupling. Results show that the calculated comprehensive risk evaluation value of fatigue failure of airport concrete runways by the proposed method is consistent with the engineering objective practical value, and can be applied to the risk evaluation of another airport concrete runway. The comprehensive risk evaluation value of concrete runway failure in the case study is 0.49 , indicating certain risks of fatigue failure. Engineering and management measures should be adopted by risk factors with large evaluation values to control the fatigue failure risks. The conclusions obtained from this study provide a novel method to fatigue failure risk evaluation of airport concrete runways and an airport risk management idea for reference.
\end{abstract}

Keywords: Airport concrete runway, Fatigue failure, Risk evaluation methodology

\section{Introduction}

With the continuously increasing traveling requirements of people recently, the civil aviation industry has achieved rapid developments, which, however, induce potential safety problems. A runway is one of the important components of airports, and it is vital to the taking off and landing stage of airplanes. With the increase in flight number and the proportion of heavy airplanes, runways are often under full loads and even overloads, and they undergo irregular impacts of movable loads generated by taxiing of airplanes and impulse loads generated by landing. The fatigue strength of airport runways is facing severe tests [1-2]. Once fatigue failure of a runway occurs, it will surely cause bumps of airplanes on the runway and thereby influence the comfort of passengers, even triggering injury accidents of passengers. In addition, pavement damages influence the runway or landing safety of airplanes and cause threats to the life safety of crews and passengers. As one of the primary materials at airport runways nowadays, concrete has the characteristics of high hardness and strength, and it can generate macroscopic brittle fractures under long-term impacts. Runway safety shall be centered on prevention. Therefore, failure risk evaluation of concrete runways at airports becomes one of the important means in runway safety management at airports. Fatigue failure of concrete runways has many influencing factors, such as the mechanical properties of runway materials, external environment, bearing loads, and security accidents of a damaged runway structure. These influencing factors have complicated relations. Recognizing and distinguishing the influencing factors of runway failure risks and conducting a comprehensive risk evaluation of runway failure are the bases for fatigue failure risk control of runways.

Nevertheless, studies on runway failure risks are rare. Concerning runway risk assessment, most scholars have evaluated the risks of unsafe incidents of a specific type of runway, such as runway invasion and overshooting the runway. These studies have emphasized artificial risks rather than runway risks. A runway is the direct carrier of airplanes, and its structural stability has high significance to the safe operation of airplanes. Some scholars have performed theoretical studies on the stability of runways under different environments and conditions from perspectives of runway foundation and local runway damages at airports. However, few scholars have focused on the fatigue failure risk evaluation of runways based on relevant influencing factors. To address these problems, this study analyzed the internal and external causes of the fatigue failure risks of runways comprehensively, screened the fatigue failure risk factors of airport runways, and determined the key risk factors. Lastly, a fatigue failure risk evaluation method for concrete runways was proposed. The proposed method has high significance in decreasing failure risks and improving the safety management level of runways. 


\section{State of the Art}

Plenty of scholars have performed studies on the influencing factors of the fatigue failure risks of concrete runways. Zhang et al. [3] indicated that the movable loads of airplanes had important impacts on the structural stability of runways and analyzed the distribution laws of maximum additional dynamic stress generated by different pavement structures and airplane modes on the top surface of soil matrixes. On the basis of theoretical analysis and field investigation, Garg [4] and Gopalakrishnan [5] emphasized that loads could induce damages to airport runways. Wang et al. [6] analyzed the local failure risk of runways mainly from the pavement damages of airport runways. Ling et al. [7] demonstrated that the service life of runways is directly correlated with taking off and landing flights at airports and the pavement roughness of runways. Shah et al. [8], Worrell et al. [9], Dong et al. [10], Chen et al. [11], and Loprencipe et al. [12] believed that pavement roughness at airports is of high significance to the safe operation of runways and that uneven pavement would increase loads, thus intensifying the damages of runways. Hence, they conducted a detailed study on a roughness test method for airport runways. Runways are a kind of traffic road, and the influencing factors of the damages of traffic roads can provide references to those of runways. Concerning the influencing factors of pavement failures, most scholars have concentrated on the influences of runway loads and the mechanical properties of materials on pavement failures. Chai et al. [13] studied the permanent deformation of the soft foundation of roads caused by traffic loads. Zhao et al. [14] indicated through a study that given different pavement structures and strength parameters of soil base, the depth and degree of influence caused by movable loads also vary. In addition, concrete is the main material of concrete runways, and the influencing factors of concrete damages are also a part that is not ignorable during the analysis of the influencing factors of concrete runways. Many associated studies have been reported. Jia et al. [15] showed that temperature can influence concrete failure to some extent, and the influencing laws of temperature on the mechanical properties of concrete were gained through an experiment. With the increase in temperature, its influences on the mechanical properties of concrete declined gradually. $\mathrm{Gu}$ et al. [16] concluded the failure characteristics and process of concretes under point impact through an experiment. Khosravani et al. [17] demonstrated the impacts of the material composition of concrete on its shock strength Li et al. [18] conducted an experimental study on the relation between the times of load impacts and the structural failure of concrete. They concluded that the damage degree of concrete was positively related to the times of impact. Huang et al. [19] indicated that the moisture content of concrete could also affect its structural stability to some extent. The preceding analysis has shown many influencing factors of concrete runway damages. However, most scholars have focused on only a type of influencing factor. No scholars have performed systematic and comprehensive analysis on the influencing factors of the fatigue failures of concrete runways yet.

Existing studies on the risk evaluation of airport runways mainly focus on the risk evaluation of a type of security accident, such as runway incursion [20] and overshooting the runway. The studies on the pavement failure risks of runways are blank. Concrete is the main material in airports. The risk evaluation of concrete structures can provide important references to the risk evaluation of runway failure at airports. On the basis of a comprehensive evaluation of the risks of dike bursting, Huang et al. [21] assessed an evaluation index system for dike bursting risks. Subsequently, the evaluation values of qualitative and quantitative risk indexes were gained through threshold and expert scoring methods. Moreover, the weights of different risk factors were gained through the G1 method, and the comprehensive evaluation value of dike bursting risk was calculated.

To sum up, few integral studies exist on the risk evaluation of concrete runways, and most studies focus on the influences of a type of risk factors on the structural stability of runways or the mechanical properties of concrete. Given that research contents are relatively limited within a certain aspect, research results only represent the influence degree of a type of factors on runway failures and cannot reflect the comprehensive failure risks of runways. In addition, single-factor risk evaluation neither is in favor of transverse comparison among different factors nor can extract key influencing factors from all factors. The fatigue failure of runways is the consequence of a multifactor comprehensive effect. At present, few studies exist on the overall failure risk of runways under the influences of multiple factors.

With respect to existing studies, all the influencing factors of the fatigue failure of concrete runways were analyzed comprehensively, and the key influencing factors were extracted. An evaluation index system was established. All risk factors were classified, and quantization of different indexes was performed. Moreover, the weights of influencing factors were determined using the G1 method. Lastly, the comprehensive risk evaluation values of the fatigue failure of concrete runways and the contributions of different risk factors were calculated through layer-by-layer weight coupling calculation. Research results can provide important guidance to the recognition and daily control of the key influencing factors of the fatigue failure risk of concrete runways.

\section{Methodology}

3.1 Analysis on the influencing factors of the fatigue failure of concrete runways and determination of risk factors ware model

Analyzing the influencing factors of the fatigue failure of concrete runways is the premise for risk evaluation. In this study, internal and external influencing factors were analyzed. Internal factors mainly refer to the factors about the runway, such as mechanical parameters, pavement roughness, and service life. External factors mainly consider the loads on runways, external environment, daily maintenance, and other causes of runway damages. On the basis of a full analysis of influencing factors, factors that have significant impacts on the fatigue failure of runways were extracted as risk factors, which laid a foundation for follow-up risk evaluation.

\subsection{Quantization of risk factors}

From reference [21], risk factors can be divided into "very large type," "very small type," "moderate type," and "interval type." Specifically, the "very large type" shows a high-risk degree if the numerical value is high. Similarly, the "very small type" shows a high-risk degree if the numerical value is low. The "moderate type" shows a high-risk degree as the numerical value approaches the middle. The "interval 
type" is at the risk state when the numerical value is in an interval and the risk degree increases while approaching the interval. Due to the differences among quantitative factors in units and orders of magnitudes present incommensurability, this causes inconvenience for comparing the values of comprehensive evaluation factors. Therefore, dimensionless treatment of all factors is necessary before evaluation, and differences in measurement units and values must be eliminated using a certain measurement method. The real values must be converted into factor evaluation values. In this study, the threshold method was applied to the dimensionless treatment of risk factors, which required the determination of the maximum and minimum of all factors in addition to the real values of risk factors. The specific process is as follows:

The evaluation values of the "very large type" can be expressed as

$$
y=\frac{x-x_{\text {min }}}{x_{\text {max }}-x_{\text {min }}}=\left\{\begin{array}{cl}
1 & x \leq x_{\text {min }} \\
\frac{x-x_{\text {min }}}{x_{\text {max }}-x_{\text {min }}} & x_{\text {min }} \leq x \leq x_{\text {max }} \\
0 & x \geq x_{\text {max }}
\end{array}\right.
$$

Where $y$ is the evaluation value of evaluation factors, $\mathrm{x}$ is the measured value of dimensional factors, $x_{\max }$ is the maximum of dimensional factors, and $x_{\min }$ is the minimum of dimensional factors.

The evaluation values of the "very small type" can be expressed as

$$
y=\frac{x_{\text {max }}-x}{x_{\text {max }}-x_{\text {min }}}=\left\{\begin{array}{cl}
1 & x \leq x_{\text {min }} \\
\frac{x_{\text {max }}-x}{x_{\text {max }}-x_{\text {min }}} & x_{\text {min }} \leq x \leq x_{\text {max }} \\
0 & x \geq x_{\text {max }}
\end{array}\right.
$$

Given that the "very large type" or "very small type" includes all unilateral factors, this method is only for unilateral factors. Bilateral factors are also called intervaltype factors, and their evaluation values can be expressed as

$$
y=\exp \left[-k\left(x-\frac{x_{\min }+x_{\max }}{2}\right)^{2}\right]
$$

Given that the values of qualitative factors generally have fuzzy and nonquantitative characteristics, describing qualitative factors by using an accurate value is difficult. At present, expert scoring methods and fuzzy mathematics are common quantization methods for qualitative factors. With the characteristics of simple operation and strong practicability, the expert scoring method is widely applied in the studies and treatment of qualitative problems in many fields. The specific steps are introduced in the following text.

A total of $n$ experts are invited to give evaluation values $B_{j}\left(U_{i}\right)(i=1,2,3 \cdots, m, \mathrm{j}=1,2,3 \cdots, n)$ to qualitative indexes $U_{1}, U_{2}, U_{3} \ldots U_{m}$ ( $m$ indexes). The final evaluation value $\left(V_{i}\right)$ of factor $U_{j}$ is generally gained from the comprehensive calculation of the scores of $n$ experts. Three common methods are used to calculate experts' scores:
(1) Full average method. It can obtain the factor evaluation value through the following equation:

$$
V_{i}=\frac{1}{n} \sum_{j=1}^{n} B_{\mathrm{j}}\left(U_{i}\right)
$$

The full average method ignores the differences of invited experts in factor recognition and understanding, calculates the sum of scores of all experts, and averages the scores to yield the final evaluation value. Therefore, this method requires a premise of approximately consistent understanding of all experts on factors.

(2) Intermediate average method. This method can obtain factor evaluation values in accordance with the following equation:

$$
V_{i}=\frac{1}{n-2}\left(\sum_{j=1}^{n} B_{\mathrm{j}}\left(U_{i}\right)-B_{\text {max }}\left(U_{i}\right)-B_{\text {min }}\left(U_{i}\right)\right)
$$

Where $B \max \left(U_{i}\right)$ is the highest expert score on factor $U_{i}$. $B \min \left(U_{i}\right)$ is the lowest expert score on factor $U_{i}$. The intermediate average method is mainly used in the situation in which great differences exist among expert scores.

(3) Weighted average method. It can generate factor evaluation values in accordance with the following equation:

$$
V_{i}=\frac{1}{n} \sum_{j=1}^{n}\left[B_{\mathrm{j}}\left(U_{i}\right) \times \alpha_{\mathrm{j}}\right]
$$

Where $\alpha_{j}$ is the weight of the $j^{\text {th }}$ expert. The advantage of the weighted average method is that it considers the differences of experts in factor understanding. Generally, more authoritative experts consider closer practical situations for the evaluation values of risk factors, thus resulting in a higher proportion of expert scores.

\subsection{Weighting process of risk factors and calculation of risk values}

In the fatigue failure risk evaluation of concrete runways at airports, each risk factor has inconsistent contributions to runway damages. Therefore, a weight coefficient should be given to risk factors to reflect their contributions to runway damages. At present, objective and subjective weighting methods are commonly used in the weighting of evaluation indexes. The weight coefficient is difficult to determine because objective practical systems present different characteristics due to the influences of the environment or the subjective wishes of evaluators during operation. Hence, the weight coefficient is determined via objective ways in most cases. The analytic hierarchy process (AHP) is a subjective weighting method, which is used frequently. However, it encounters many factors and incurs a large scale. In AHP, a judgment matrix hardly meets the requirement for consistency. On this basis, the weights of risk factors were determined using the G1 method, which does not require a consistency test. The specific steps of AHP are as follows:

(1) Importance sequence of risk factors

If $s$ indexes in the index system are $x_{1}, x_{2}, \cdots, x_{s}$, all risk evaluation factors that have been established are arranged in order in accordance with importance. Descending or ascending orders of importance are acceptable. In this study, all risk evaluation factors were 
arranged in descending order in accordance with the importance and denoted as $x_{1}^{\prime}, x_{2}^{\prime}, \ldots, x_{s}^{\prime}$. Specifically, the importance of $x^{\prime}{ }_{i}$ is higher than that of $x_{i+1}^{\prime}(i=1,2, \cdots$, $s$-1). The specific sequencing principle can be formulated by experts or follow the importance of relevant evaluation criteria.

(2) Determining the relative importance degree between adjacent risk factors

Suppose the weights of $s$ risk factors are $\omega_{1}, \omega_{2}, \cdots, \omega_{s}$. The ratio between the weights of two adjacent factors was calculated as follows: $r_{k}=\omega_{k-1} / \omega_{k}$, where $k=s, s-1, s-2, \cdots$, 3,2 . In this way, the relative importance among different indexes was calculated in accordance with the order relations among previous indexes. When the number of factors $(s)$ is relatively high, it can be determined as $r_{s}=1$. The values of $r_{k}$ can be referred to Table 1 .

Table 1. Relative importance among risk factors

\begin{tabular}{c|c}
\hline$r_{k}$ value & Importance description \\
\hline 1 & $x_{k-1}$ is as important as $x_{k}$ \\
1.2 & $x_{k-1}$ is slightly more important than $x_{k}$ \\
1.4 & $x_{k-1}$ is obviously important than $x_{k}$ \\
1.6 & $x_{k-1}$ is strongly important than $x_{k}$ \\
1.8 & $x_{k-1}$ is extremely important than $x_{k}$ \\
\hline
\end{tabular}

The final value of relative importance between two risk factors $(r k)$ is given by authoritative experts in accordance with Table 1. To meet the principle of importance sequencing, $r k$ and $r k-1$ must meet the following relation:

$$
r_{k} \times r_{k-1}>1
$$

(3) Calculation of weight coefficient

If $r k$ given by experts meets Eq. (7) mostly, the weights of the risk factor $\mathrm{k}\left(\omega_{k}\right)$ can be calculated as:

$$
w_{s}=\left(1+\sum_{k=2}^{s} \prod_{i=k}^{s} r_{i}\right)^{-1}, w_{k-1}=r_{k} w_{k}
$$

(4) Calculation for the fatigue failure risk evaluation of concrete runways at airports

The weights of influencing factors in all layers of index systems were determined using the G1 method. In combination with the gained evaluation value, the comprehensive risk value of fatigue failure of concrete runways and the contribution values of different influencing factors were calculated through layer-by-layer superposing coupling.

\section{Results Analysis and Discussion}

\subsection{Determination of the failure risk factors of concrete runways}

Internal risk factors refer to the influencing factors of the mechanical properties of concrete runways. The mechanical parameters of materials directly influence their mechanical properties, including porosity, internal friction angle, compressive strength, permeability, cohesive force, and dry density. These risk factors can be gained through field sampling and laboratory tests. The crack density of pavement can also influence the mechanical characteristics of runways to some extent. Concrete runways with a high crack density show weak compressive strength or shear capacity, and they are easy to be damaged under instantaneous impact loads during the landing of airplanes and movable loads during taxiing of airplanes. Roughness is one of the main parameters of airport runways. Low roughness implies high roughness of pavement, and the bumps during taxiing of airplanes are serious. Consequently, vertical loads on pavement increase and fluctuate. The irregular growth of vertical loads can also intensify the damages to concrete runways. From reference [22], the longterm operation will surely cause small damages to concrete runways, and the internal damages become significant with the increase in service time. To sum up, the internal risk factors of concrete runways can be gained.

Through a comprehensive analysis of the influencing factors of concrete runway failures at airports, external influencing factors can be considered from the four main aspects of loads, maintenance, external environment, and others. Specifically, loads mainly refer to the bearing loads of runways during daily operation. The runway failure risks are high under high carrying loads. Load is directly related to the number of taking-off flights, airplane mode, and heavy landing events at airports. Maintenance refers to the daily maintenance of airport runways, and it is mainly reflected by two index factors: daily inspection period of runways and daily maintenance cost of runways. The external environment mainly includes the influences of weather factors [23] and airport positions. For weather factors, some scholars have demonstrated that temperature and humidity could influence the mechanical properties of concrete materials. Concrete expands, and its strength declines with the increase in temperature. Under the same load levels, the probability of concrete damages is positively related to temperature. The internal molecular bonding strength and shear strength of concrete decrease with the increase in humidity. Weather changes often cause changes in the temperature and humidity of the runway operation environment. Hence, the influences of weather factors must be considered. In addition, the geological position of airports can influence runway stability significantly. Influenced by geology, airport runways in mountainous regions are easy to be damaged. On the contrary, the geological environment of airports in plains is stable, thus resulting in relatively high runway stability. Considerable attention must also be given to pavement damages caused by emergency events, such as the rear-end collision accident proneness of airplanes and pavement failures caused by other factors. The abovementioned external factors are listed in Table 2. On the basis of the statistics of risk factors, a risk index system for the fatigue failure of airport runways was established. The results are shown in Table 2 .

Table 2. Risk factors for the fatigue failure of airport

\begin{tabular}{|c|c|c|c|}
\hline $\begin{array}{c}\text { Risk } \\
\text { category }\end{array}$ & \multicolumn{2}{|c|}{ Risk factors } & factor type \\
\hline $\begin{array}{l}\text { Internal } \\
\text { factors }\end{array}$ & \multicolumn{2}{|c|}{$\begin{array}{c}\text { porosity } \\
\text { internal friction angle } \\
\text { compressive strength } \\
\text { impermeability } \\
\text { cohesive force } \\
\text { dry density } \\
\text { crack density } \\
\text { IRI } \\
\text { service time }\end{array}$} & $\begin{array}{l}\text { quantitative } \\
\text { quantitative } \\
\text { quantitative } \\
\text { quantitative } \\
\text { quantitative } \\
\text { quantitative } \\
\text { quantitative } \\
\text { quantitative } \\
\text { quantitative }\end{array}$ \\
\hline $\begin{array}{l}\text { External } \\
\text { factors }\end{array}$ & load factors & $\begin{array}{l}\text { number of flights } \\
\text { proportion of heavy }\end{array}$ & $\begin{array}{l}\text { quantitative } \\
\text { quantitative }\end{array}$ \\
\hline
\end{tabular}
runways 


\begin{tabular}{c|c|c|c}
\hline & $\begin{array}{c}\text { airplanes } \\
\text { heavy landing event }\end{array}$ & quantitative \\
\cline { 2 - 4 } & $\begin{array}{c}\text { maintenance } \\
\text { factors }\end{array}$ & $\begin{array}{c}\text { daily inspection } \\
\text { period of runway } \\
\text { maintenance cost }\end{array}$ & $\begin{array}{c}\text { quantitative } \\
\text { quantitative }\end{array}$ \\
\cline { 2 - 4 } & $\begin{array}{c}\text { environmental } \\
\text { factors }\end{array}$ & $\begin{array}{c}\text { airport position } \\
\text { weather factor }\end{array}$ & $\begin{array}{c}\text { qualitative } \\
\text { qualitative }\end{array}$ \\
\cline { 2 - 4 } others & $\begin{array}{c}\text { rear-end collision } \\
\text { accidents }\end{array}$ & qualitative \\
\cline { 2 - 3 } & $\begin{array}{c}\text { Other situations of } \\
\text { pavement damages }\end{array}$ & qualitative \\
\hline
\end{tabular}

\subsection{Quantization of risk factors and weighting results}

For the convenience of a quantitative study, all constructed indexes must be classified first into qualitative and quantitative indexes. Quantization analyses of qualitative and quantitative indexes were conducted. In this study, all indexes were analyzed one by one and then classified. The results are shown in Table 2.

An engineering practical case study was performed in $A$ airport. The quantization of the fatigue failure risk factors of runways in $A$ airport is introduced as follows.

\section{(1) Practical situations of risk factors}

For internal factors, field samples were collected from concrete runway materials in $A$ airport to test the mechanical parameters. On this basis, the risk factor values related to the mechanical parameters of concrete were determined. Moreover, the roughness of concrete runways in $A$ airport was tested using the international roughness index (IRI) test method. A statistical analysis on the crack area in the unit runway area and the operation years of the runway was performed. From the analysis, statistics on the practical values of internal factors in $A$ airport were made (Table 3 ).

Table 3. Practical values of internal risk factors

\begin{tabular}{c|c}
\hline Internal risk factors & Practical values \\
\hline porosity & 0.05 \\
Impermeability/Mpa & 0.5 \\
internal friction angle ${ }^{\circ}$ & 52 \\
cohesive force $/ \mathrm{Mpa}$ & 2.3 \\
dry density $/\left(\mathrm{g} \cdot \mathrm{cm}^{-3}\right)$ & 2.3 \\
compressive strength/Mpa & 55 \\
crack density/ $\left(\mathrm{m}^{2} / \mathrm{m}^{2}\right)$ & 0.05 \\
IRI & 1.5 \\
service time/year & 10 \\
\hline
\end{tabular}

For external factors, the number of flights focuses on the daily average number of taking-off and landing flights in the airport. The proportion of heavy airplanes mainly focuses on the proportion of heavy airplanes in the daily average number of taking-off and landing flights. At present, a heavy landing event is mainly judged by the vertical acceleration at landing. In this way, the mean vertical acceleration in the heavy landing event can be approximately expressed as the heaving landing risk factor. The daily inspection period of the runway mainly concentrates on the daily inspection and maintenance period of the airport, and maintenance cost emphasizes the monthly average maintenance cost of the airport. Airport position mainly describes the geological position of the airport. Weather factors mainly focus on the statistics of the annual number of rainy and snowy days and the number of high-temperature days (number of days with a temperature over $40^{\circ} \mathrm{C}$ ) in the airport. Rear-end collision accident proneness focuses on the statistics of occurrences of rear-end collision accidents in the airport. If rear-end collision accidents occur, runway damages caused by rearend collision accidents are described. Other situations of pavement damages mainly focus on various factors that cause pavement failures of the airport. Practical descriptions of external factors are shown in Table 4.

\begin{tabular}{|c|c|c|}
\hline External factors & Risk factors & $\begin{array}{c}\text { Practical descriptions of } \\
\text { external factors }\end{array}$ \\
\hline \multirow{3}{*}{ load factors } & number of flights & 875 sorties \\
\hline & $\begin{array}{c}\text { proportion of heavy } \\
\text { airplanes }\end{array}$ & $45 \%$ \\
\hline & heavy landing event & $1.8 \mathrm{~g}$ \\
\hline \multirow{2}{*}{$\begin{array}{l}\text { maintenance } \\
\text { factors }\end{array}$} & $\begin{array}{c}\text { daily inspection period } \\
\text { of runway }\end{array}$ & 2 hours \\
\hline & maintenance cost & 0.42 Million RMB \\
\hline \multirow[b]{2}{*}{$\begin{array}{l}\text { environmental } \\
\text { factors }\end{array}$} & airport position & located in the plain area \\
\hline & weather factors & $\begin{array}{c}\text { the annual average } \\
\text { rainfall and snow days } \\
\text { are } 120 \text { days, and the } \\
\text { high-temperature days } \\
\text { are } 52 \text { days }\end{array}$ \\
\hline \multirow[b]{2}{*}{ others } & $\begin{array}{l}\text { rear-end collision } \\
\text { accidents }\end{array}$ & $\begin{array}{l}\text { tail-wiping incidents do } \\
\text { not cause damage to the } \\
\text { runway surface }\end{array}$ \\
\hline & $\begin{array}{l}\text { Other situations of } \\
\text { pavement damages }\end{array}$ & $\begin{array}{l}\text { The presence of } \\
\text { emergency braking } \\
\text { caused minor damage to } \\
\text { the road surface }\end{array}$ \\
\hline
\end{tabular}

\section{(2) Quantization results of risk factors}

With respect to the risk factors of the mechanical parameters of concrete runways in the airport, evaluation values were calculated on the basis of relevant design standards. The value range of crack density is generally between 0 and 0.5 . A runway with a high crack density is easy to be damaged. The roughness standard proposed by the University of Michigan was applied in this study. A road is determined as an unserviceable pavement when IRI exceeds 3.47. For this reason, the IRI value ranges between 0 and 3.47. Concrete runways in airports are one type of concrete road. At present, the service time of concrete roads is generally 20-100 years. Nevertheless, concrete runways in airports are different from other concrete roads. Concrete runways serve for airports. Owing to the heavy weight of airplanes, the pavement loads of airplanes during taking-off and landing taxiing are significantly higher than the pavement loads of vehicles. Hence, the upper limit of service years of concrete runways in airports was determined as 20 years in this study. Therefore, the service life range of airports was 0-20 years. The number of flights mainly considers the highest permissible take-off and landing flights in the airport design, which refers to 1,500 . Hence, the number of flights ranges between 0 and 1,500. No corresponding standard exists on the proportion of heavy airplanes in airports. Therefore, this study set the upper limit as the situation when all taking-off and landing airplanes are heavy airplanes in the airport and set the lower limit as the situation when no heavy airplanes exist in the airport. The proportion of heavy airplanes is between 0 and $100 \%$. A heavy landing event refers to security accidents during the operation of airports. In this study, the contributions of a security event to pavement failure were reflected mainly by vertical acceleration. The impact force of airplanes to the landing point increases at the occurrence of the heaving landing of airplanes. If the impact force is higher than the shock strength of concrete, microdamage occurs in the concrete. On this basis, the shock strength of concrete was used as the reference for the backward deduction of the vertical acceleration of airplanes under this condition. The deduced vertical acceleration was used as the upper reference limit of heavy landing events. In 
accordance with the calculation, the value range of heavy landing events was $0-2 \mathrm{~g}$. The daily inspection period of runways mainly focuses on $0.5-24 \mathrm{~h}$. The runway maintenance cost varies significantly for different airports. Key attention was paid to the statistics of the maintenance cost of some airports at the same level. The reference range of runway maintenance cost was 0.2-1 million yuan.

In accordance with the above analysis results of quantitative factors, the evaluation values of quantitative factors were calculated using Eqs. (1)-(3). The results are listed in Table 5.

Table 5. Evaluation values of quantitative factors

\begin{tabular}{c|c|c|c}
\hline $\begin{array}{c}\text { Qualitative } \\
\text { factors }\end{array}$ & $\begin{array}{c}\text { Evaluation } \\
\text { values }\end{array}$ & $\begin{array}{c}\text { Qualitative } \\
\text { factors }\end{array}$ & $\begin{array}{c}\text { Evaluation } \\
\text { values }\end{array}$ \\
\hline porosity & 0.67 & IRI & 0.43 \\
impermeability & 0.50 & service time & 0.67
\end{tabular}

\begin{tabular}{c|c|c|c}
$\begin{array}{c}\text { internal friction } \\
\text { angle }\end{array}$ & 0.48 & $\begin{array}{c}\text { number of flights } \\
\text { proportion of } \\
\text { cohesive force }\end{array}$ & 0.58 \\
dry density & 0.68 & $\begin{array}{c}\text { heavy landing } \\
\text { event } \\
\text { daily inspection } \\
\text { period of runway }\end{array}$ & 0.45 \\
$\begin{array}{c}\text { strength } \\
\text { crack density }\end{array}$ & 0.25 & $\begin{array}{c}\text { maintenance cost } \\
\text { mantessive }\end{array}$ & 0.06 \\
\hline
\end{tabular}

For qualitative factors, eight experts were invited to give scores to four qualitative indexes, and the score range was 0 1. The qualitative factor with a higher score has higher risks to cause pavement damages. Lastly, the evaluation values of qualitative factors were calculated from Eq. (6). The results are listed in Table 6.

Table 6. Evaluation values of qualitative factors

\begin{tabular}{|c|c|c|c|c|c|c|c|c|c|}
\hline \multirow{3}{*}{ Qualitative factors } & \multicolumn{8}{|c|}{ Experts and their weight } & \multirow{3}{*}{ Evaluation values } \\
\hline & 1 & 2 & 3 & 4 & 5 & 6 & 7 & 8 & \\
\hline & 0.18 & 0.14 & 0.14 & 0.12 & 0.12 & 0.1 & 0.1 & 0.1 & \\
\hline Airport position & 0.3 & 0.25 & 0.28 & 0.35 & 0.29 & 0.4 & 0.22 & 0.32 & 0.30 \\
\hline Weather factors & 0.5 & 0.44 & 0.46 & 0.56 & 0.48 & 0.62 & 0.42 & 0.51 & 0.49 \\
\hline Rear-end collision accidents & 0.67 & 0.56 & 0.6 & 0.63 & 0.63 & 0.59 & 0.7 & 0.65 & 0.63 \\
\hline Other situations of pavement damages & 0.82 & 0.7 & 0.75 & 0.78 & 0.7 & 0.69 & 0.81 & 0.79 & 0.75 \\
\hline
\end{tabular}

\section{(3) Weighting results of risk factors}

From the preceding analysis, the weights of internal and external factors on the top layer were determined using the G1 method first. Then, the weights of bottom risk factors were calculated directly for internal factors. For external factors, the weights of four intermediate-layer factors, including load factors, maintenance factors, environmental factors, and others, were calculated. Subsequently, the weights of risk factors in the intermediate layer were calculated one by one. A statistical analysis on the weights of different risk factors was conducted. The results are shown in Table 7.

Table 7. Weights and evaluation values of risk factors

\begin{tabular}{|c|c|c|c|c|c|c|c|c|c|}
\hline \multirow{19}{*}{$\begin{array}{c}\text { Comprehensive } \\
\text { risk evaluation } \\
\text { value of fatigue } \\
\text { damage of airport } \\
\text { concrete runway } \\
(0.49)\end{array}$} & $\begin{array}{c}\text { Top } \\
\text { factors }\end{array}$ & Weights & $\begin{array}{c}\text { Evaluation } \\
\text { value }\end{array}$ & $\begin{array}{c}\text { Intermediate } \\
\text { factors }\end{array}$ & Weights & $\begin{array}{c}\text { Evaluation } \\
\text { value }\end{array}$ & $\begin{array}{c}\text { Underlying } \\
\text { factors }\end{array}$ & Weights & $\begin{array}{c}\text { Evaluation } \\
\text { value }\end{array}$ \\
\hline & \multirow{9}{*}{$\begin{array}{l}\text { internal } \\
\text { factors }\end{array}$} & \multirow{9}{*}{0.38} & \multirow{9}{*}{0.46} & \multirow[t]{9}{*}{ (1) } & \multirow{9}{*}{--} & \multirow{9}{*}{--} & porosity & 0.09 & 0.67 \\
\hline & & & & & & & Impermeability & 0.09 & 0.50 \\
\hline & & & & & & & $\begin{array}{c}\text { internal friction } \\
\text { angle }\end{array}$ & 0.09 & 0.48 \\
\hline & & & & & & & cohesive force & 0.09 & 0.68 \\
\hline & & & & & & & dry density & 0.09 & 0.57 \\
\hline & & & & & & & $\begin{array}{c}\text { compressive } \\
\text { strength }\end{array}$ & 0.09 & 0.25 \\
\hline & & & & & & & crack density & 0.15 & 0.10 \\
\hline & & & & & & & IRI & 0.2 & 0.43 \\
\hline & & & & & & & service time & 0.11 & 0.67 \\
\hline & \multirow{9}{*}{$\begin{array}{l}\text { external } \\
\text { factors }\end{array}$} & \multirow{9}{*}{0.62} & \multirow{9}{*}{0.51} & \multirow{3}{*}{ load factors } & \multirow{3}{*}{0.36} & \multirow{3}{*}{0.67} & $\begin{array}{c}\text { number of } \\
\text { flights }\end{array}$ & 0.29 & 0.58 \\
\hline & & & & & & & $\begin{array}{c}\text { proportion of } \\
\text { heavy airplanes }\end{array}$ & 0.3 & 0.45 \\
\hline & & & & & & & $\begin{array}{c}\text { heavy landing } \\
\text { event }\end{array}$ & 0.41 & 0.90 \\
\hline & & & & \multirow{2}{*}{$\begin{array}{l}\text { maintenance } \\
\text { factors }\end{array}$} & \multirow[t]{2}{*}{0.30} & \multirow[t]{2}{*}{0.27} & $\begin{array}{c}\text { daily inspection } \\
\text { period of } \\
\text { runway } \\
\end{array}$ & 0.69 & 0.06 \\
\hline & & & & & & & $\begin{array}{c}\text { maintenance } \\
\text { cost }\end{array}$ & 0.31 & 0.73 \\
\hline & & & & \multirow{2}{*}{$\begin{array}{l}\text { environmental } \\
\text { factors }\end{array}$} & \multirow{2}{*}{0.14} & \multirow{2}{*}{0.41} & airport position & 0.44 & 0.30 \\
\hline & & & & & & & weather factors & 0.56 & 0.49 \\
\hline & & & & \multirow{2}{*}{ others } & \multirow{2}{*}{0.20} & \multirow{2}{*}{0.67} & $\begin{array}{l}\text { rear-end } \\
\text { collision } \\
\text { accidents }\end{array}$ & 0.65 & 0.63 \\
\hline & & & & & & & $\begin{array}{c}\text { Other situations } \\
\text { of pavement } \\
\text { damages }\end{array}$ & 0.35 & 0.75 \\
\hline
\end{tabular}

\subsection{Comprehensive risk evaluation results}

The comprehensive risk values were calculated layer by layer in accordance with the evaluation values and weights of determined risk factors. The results are shown in Table 7.
The table indicates that the comprehensive risk evaluation value of the fatigue failure of the concrete runway in $A$ airport is 0.49 , showing certain risks. This condition requires managers to adopt engineering or management means to 
lower the risk value. To increase the efficiency of control means, key risk factors with great contributions to the comprehensive risk value must be recognized in advance. The contributions of different risk factors to the comprehensive risk value can be calculated from Table 7 . The results are shown in Table 8 .

Table 8. Contributions of different risk factors to the comprehensive risk value

\begin{tabular}{|c|c|c|c|}
\hline Risk factors & Contributions & Risk factors & Contributions \\
\hline porosity & 0.023 & IRI & 0.033 \\
\hline Impermeability & 0.017 & service time & 0.028 \\
\hline $\begin{array}{l}\text { internal friction } \\
\text { angle }\end{array}$ & 0.016 & $\begin{array}{c}\text { number of } \\
\text { flights }\end{array}$ & 0.038 \\
\hline cohesive force & 0.023 & $\begin{array}{c}\text { proportion of } \\
\text { heavy airplanes }\end{array}$ & 0.030 \\
\hline dry density & 0.019 & $\begin{array}{c}\text { runway include } \\
\text { heavy landing } \\
\text { event }\end{array}$ & 0.082 \\
\hline $\begin{array}{l}\text { compressive } \\
\text { strength }\end{array}$ & 0.009 & $\begin{array}{c}\text { daily inspection } \\
\text { period of } \\
\text { runway }\end{array}$ & 0.008 \\
\hline crack density & 0.06 & $\begin{array}{c}\text { maintenance } \\
\text { cost }\end{array}$ & 0.042 \\
\hline airport position & 0.011 & $\begin{array}{l}\text { rear-end } \\
\text { collision } \\
\text { accidents }\end{array}$ & 0.051 \\
\hline weather factors & 0.024 & others & 0.033 \\
\hline
\end{tabular}

Table 8 demonstrates that the risk factors contributing to concrete runway damages include heavy landing events, rear-end collision accidents, maintenance cost, and the number of flights, IRI, and the proportion of heavy airplanes. Among them, heavy landing events and rear-end collision accidents cause the most serious damages to runways. These two factors could be controlled by improving the landing technique of pilots and strengthening landing safety management. Moreover, the risk evaluation values could be decreased by increasing runway maintenance costs and controlling the proportion of heavy airplanes appropriately.

\section{Conclusion}

In this study, the internal and external influencing factors of the fatigue failures of runways were analyzed and 18 fatigue failure risk factors of concrete runways were recognized. They are classified into quantitative and qualitative factors. Consistency treatment was implemented on quantitative and qualitative factors through threshold and expert scoring methods. On this basis, the weights of risk factors were determined using the G1 method, and the comprehensive risk evaluation value was calculated. Lastly, an engineering practical case study was conducted in an airport. The weights and evaluation values of the 18 risk factors and the comprehensive risk evaluation values of fatigue failure of concrete runways are deduced. The main conclusions are as follows:

(1) From multiple aspects of the mechanical parameters of airport runways, pavement roughness, service life, external environment, carrying load, security events, and daily maintenance, 18 fatigue failure risk evaluation factors for concrete runways are established scientifically, which offset blanks in the risk evaluation indexes of runway damages.

(2) Through combining threshold, expert scoring, and G1 methods, a fatigue failure risk assessment method for concrete runways is proposed. An engineering practical study in $A$ airport is performed. The proposed method is verified feasible in accordance with the comparison between field data and field investigation data.

(3) High-risk factors of the fatigue failures of concrete runways in airports are concluded through the case study in $A$ airport. The factors include heavy landing events; rear-end collision incidents, maintenance cost, and the number of flights, IRI, and the proportion of heavy airplanes. Heavy landing events and rear-end collision incidents have the greatest contributions to runway failure at airports. The comprehensive risk value can be decreased by improving the landing technology of pilots and strengthening landing safety management.

(4) The comprehensive risk evaluation value of concrete runway failures in $A$ airport is 0.49 , indicating certain failure risks of the runway. Managers should adopt control means to lower the damage risks.

In sum, the key risk factors of the fatigue failure of airport runways can be recognized by the constructed risk evaluation index system and the proposed risk assessment method. Managers can adopt countermeasures in accordance with specific risk factors. Additionally, the comprehensive risk evaluation value of concrete runway failure at airports is conducive to have a macroscopic understanding of runway failure risks and implement a transverse comparison of different airports.

The proposed evaluation index system and evaluation method are feasible to evaluate the fatigue failure risks of concrete runways at airports under full loads and even overloads. The evaluation results can provide accurate theoretical supports to the fatigue failure risk control of runways. However, further studies on the correlations of risk factors and their influences on comprehensive risk evaluation values and how to lower the risk values of key risk factors effectively are still needed.

\section{Acknowledgments}

This study was supported by the National Key R\&D Program of China (2019YFC0810701), Science and Technology Planning Project of Henan Province (212102310384), and Humanity and Social Science Youth Foundation of Ministry of Education of China (17YJC630124) and Fundamental Research Funds for the Central Universities (3122019065).

This is an Open Access article distributed under the terms of the Creative Commons Attribution License.

\section{References}

1. Jahangiri, M., Shamsabadi, A. A., Riahi, R., Raeiszadeh, F., Dehkordi, P. F. "Levelized cost of electricity for wind-solar power systems in Japan a review". Journal of Power Technologies, 100(3), 2020, pp. 188-210.
2. Zhao, P. X., Gao, W. Q., Han, X., Luo, W. H. "Bi-objective collaborative scheduling optimization of airport ferry vehicle and tractor". International Journal of Simulation Modelling, 18(2), 2019, pp. 355-365.

3. Zhang, J. F., Qian, J. G., Lv, X. L. "Influence scope of airport runway ground under aircraft moving loads", Chinese Journal of Geotechnical Engineering, (1), 2019, pp. 101-104. 
4. Garg, N., Hayboe, G. F. "Asphalt concrete strain responses at high loads and low speed at the national airport pavement test facility (NAPTF)", American Society of Civil Engineers, 271, 2014, pp. 114.

5. Gopalakrishnan, K., Thompson, M. R. "Assessing damage to airport pavement structure due to complex gear loads", Journal of Transportation Engineering, 132(11), 2006, pp. 888-897.

6. Wang, W., Wen, J. "Research on safety risk of aerodrome asphalt concrete runway local damages", Journal of Civil Aviation University of China, 31(2), 2013, pp. 46-50.

7. Leng, J. M., Zheng, Y. F., Yuan, J. "Prediction model of remaining life for asphalt concrete pavement of runway", Journal of Tongji University, (4), 2004, pp. 471-474.

8. Shah, A., Tighe, S., Stewart, A. "Development of a unique deterioration index, prioritization methodology, and foreign object damage evaluation models for Canadian airfield pavement management", Canadian Journal of Civil Engineering, 31(4), 2004, pp. 608-618.

9. Worrell, J. Pavement Engineering Assessment Standard, Department of US Air Force, 2004.

10. Dong, Q., Hachiya, Y., Endo, K., Himeno, K., Kawamura, A., Matsui, K. "Airport pavement roughness evaluation based on aircraft response". In: Proceedings of Spie the International Society for Optical Engineering, San Diego, CA, United States: Health Monitoring and Smart Nondestructive Evaluation of Structural and Biological Systems III, 2004, pp. 118-126.

11. Chen, Y. H., Chou, C. P. "Effects of airport pavement-profile wavelength on aircraft vertical responses", Transportation Research Record, 98, 2004, pp. 83-93.

12. Loprencipe, G., Zoccali, P. "Comparison of methods for evaluating airport pavement roughness", International Journal of Pavement Engineering, 32, 2017, pp. 1-10.

13. Chai, J. C., Miura, N. "Traffic-load-induced permanent deformation of road on soft subsoil", Journal of Geotechnical and Geoenvironmental Engineering, 128(11), 2002, pp. 907-916.
14. Zhao, J. M., Liu, S. Y., Shi, M. L. "Experimental study on dynamic response of low embankment under traffic load", Journal of Southeast University (Natural Science Edition), 37(5), 2007, pp. 921-925.

15. Jia, B., Yang, F., Sun, K. L. "SHPB test on dynamical mechanical behavior of concrete with high temperature", Applied Mechanics and Materials, 528, 2014, pp.61-69.

16. Gu, X., Zhang, Q., Huang, D. "Wave dispersion analysis and simulation method for concrete SHPB test in peridynamics", Engineering Fracture Mechanics, 160, 2016, pp. 124-137.

17. Khosravani, M. R., Weinberg, K "A review on split Hopkinson bar experiments on the dynamic characterization of concrete". Construction and Building Materials, 190, 2018, pp.1264-1283.

18. Li, M., Zhu, Z. Q., Liu, L. "Improvement method of compression test and the dynamic damage of concrete", Journal of Shandong University (Engineering Science), 47(1), 2017, pp. 68-75.

19. Huang, H., Xu, J. X., Liu, J. L. "Impact damage assessment of GC in water environment based on fractal dimension", Journal of the Chinese Ceramic Society, 37(3), 2018, pp. 1114-1118.

20. Stroeve, S. H., Blom, H. A. P., Bakker, G. J. B. "Contrasting safety assessments of a runway incursion scenario: Event sequence analysis versus multi-agent dynamic risk modelling", Reliability Engineering and System Safety, 109(109), 2013, pp.133-149.

21. Huang, Z. F., Huang, H. Z., Jiang, S. H. "Quantification of risk factors and risk assessment for levee engineering system”, Journal of Natural Disasters, 27(4), 2018, pp. 173-179.

22. Pan, Y., Wu, C., Cheng, X., Li, V. C., He, L. "Impact fatigue behaviour of GFRP mesh reinforced engineered cementitious composites for runway pavement". Construction and Building Materials, 230, 2020, pp. 116898.

23. Sadri, S., Rahmani, F. "Novel technical and economic analysis of water and power co-generation in coastal areas". Journal of Power Technologies, 99(3), 2019, pp. 209-217. 